\title{
2 Challenges in interacting with people with dementia
}

\author{
Claudia Dinand, Margareta Halek
}

\begin{abstract}
Adequate and mutual interaction is a key factor for a good and stable relationship between people with dementia and their carers and a prerequisite for living well with dementia. The dominant features of dementia include cognitive impairment and behavioral changes in people with dementia, often referred to as "challenging". Whether communication is successful or not depends, on the one hand, on the type and degree of cognitive impairment and the skills and resources available to people with dementia and, on the other hand, on the ability of the environment to interpret and understand the utterances and the meaning of the behavior.

In the first part of this essay we begin with a description of the different concepts of challenging behavior and their theoretical assumptions and backgrounds. We then describe the particularities of the nursing perspective and show the state of the art in caring for people with dementia with challenging behavior. We will also consider current evidence on the different views on the phenomenon facing the perspective of professionals, family carers and people with dementia themselves.

In the second part, we alternately describe and reflect on a very short sequence of a micro interaction of a couple at home during a meal. With regard to current theoretical discussions, the example gives a first impression of the tiny, situational and complex interactional attunements and underlines the need for sensitive communication skills of people caring for people with dementia.
\end{abstract}

\subsection{Introduction}

Dementia has an enormous impact on daily living of people with this disease and for all surrounding them. One of the most prominent challenges in dealing with dementia is the creation of an appropriate and effective interaction. The dementia process causes direct communication impairments due to pathological changes in particular brain regions (e. g. anomia, aphasia, impairments in motor performance of speech). But the major part of communication and interaction problems is a result of misadjustment between dementia related impairments, available capabilities of the person with dementia and the competency of the environment to deal with the communication difficulties.

One of a dominant characteristic associated with dementia are, along with cognitive impairments, the changes in behavior of people with dementia. The prevalence of behavioral symptoms of people with dementia living at home is $53 \%$ in Germany (Teipel et al. 2015; Thyrian et al. 2015) and between 11-90\% international (Borsje et al. 2014). Behavioral changes are one of the first signs of dementia and they accompany 
people throughout the entire course of the disease. These behavioral changes have a lot of different names: disturbing, problematic, challenging, neuropsychiatric symptoms, need-driven, reactive, behavioral and psychological symptoms of dementia and many more (Halek 2019, 2019a).

Behavioral changes are challenging for family members and professional carers. They are disturbing and stressful and are responsible for heavy burden (Feast et al. 2016; Thyrian et al. 2015) on formal and informal carers. People with dementia showing challenging behavior are at higher risk for psychotropic drug use and use of restrains (Kunik et al. 2010). There is a higher risk of health problems, increased care dependency and hospital (Toot et al. 2013) and nursing home admissions (Toot et al. 2017). As a consequence, the behavioral changes influence the quality of life, autonomy and self-esteem negatively. For these reasons there are a lot of research efforts with regard to developing interventions which can prevent or decrease the occurrence of challenging behavior. For the home care setting the research activities focused mostly on training and counseling of caregivers on various topics (e. g. coping strategy, handling, and access to the services) (Feast et al. 2016).

\subsection{What is exactly this behavior that challenges?}

The numerous terms existing in the literature and daily language are umbrella terms for behaviors like agitation, disinhibition, aggression, irritability, euphoria, resistance to care, apathy, anxiety, hallucination and delusion and many more. The origin of the dementia related behaviors dates to the nineteenth century. The physician Esquirol used the term emotional disorder to describe senile dementia. At the beginning of the 20th century, Auguste D. was described by her doctor Alois Alzheimer in 1901 as a patient with cognitive disorders, aphasia, delusion and unpredictable behavior (crying). She went down in history as the first diagnosed Alzheimer's patient (Möller and Graeber 1998). Since then, behavioral disorders have been an important feature of dementia diagnosis. The behavioral disorder in dementia left its first traces in Medline - the most important article database in health - in 1965. These first articles discuss agitation terms of senile sclerosis. Further topics are psychoses, delusions, or so-called psychohygenic problems in nursing homes. The problem behavior as a topic also appears in the 60 to 90 years without the connection to dementia but in the general connection to geriatric patients or residents of nursing homes. In one of the first studies on "wandering”, i. e. on "apparently aimless or disoriented locomotion", residents of a nursing home are examined. It was found that although the number and quality of movement of walkers and non-walkers differ greatly from one another, there are no differences between the two groups in the so-called organic brain syndrome: the difference was in short-term memory (Snyder et al. 1978). The research activities in the $1980 \mathrm{~s}$, which marked a boom in research into behavior and dementia, started researching behavior independently of the diagnosis of dementia. One exam- 
ple is the psychologist and statistician Jiska Cohen-Mansfield, who initially based her entire agitation research on the population of elderly people in nursing homes. The cognitive limitations emerged as a strong influencing factor in this context. It is also the time of the development of the first important behavioral instruments like Cohen-Mansfield Agitation Inventory (Cohen-Mansfield, Marx, and Rosenthal 1989) or the BEHAVE-AD (Reisberg, Auer, and Monteiro 1996), which is mainly used in pharmacological research. Studies in the 1990s tried to bring some order to the topic. The IPA (International Psychogeriatric Association) introduced a change in term-from problem behavior to BPSD (behavioral and psychological symptoms of dementia) (IPA 2012). The IPA distanced itself after a comprehensible consensus process from terms with negative connotations such as problem behavior or behavioral disorders. Other instruments are being developed, including the NPI (Neuropsychiatric Inventory) (Cummings 1997) which is now the most widely used behavioral assessment tool in research and clinical practice. The development of guidelines on management of dementia related behavior started. The topic of behavior and dementia experienced a further upswing from the turn of the millennium. The discussion about the perspective on the behavior and its changes began. The differences between a medical and social perspective on the behavior were worked out. The term "challenging" behavior as a more psychosocial alternative is proposed (Bird and Moniz-Cook 2008). In addition, the research activities were launched on intervention for dealing with the behavior of people with dementia with strong focus on psychosocial aspects and non-pharmacological approaches (Moniz-Cook et al. 2011). In 2018 the Medline lists approximately 1600 publications with the keywords behavior and dementia in 2018.

As a result of the comprehensive discussion of the topic "behavior and dementia" different views, definitions and theoretical approaches are developed that exist in the science and in the clinical practice. While the theoretical, scientific perspectives are well documented in the numerous papers and can be extracted, the view of the clinical practice is less examined and can be found in practice reports, popular literature and few scientific papers. The discussion about the "right" view or term or definition is not trivial because how we, the practitioners, families and researcher see and interpret the behavior of people with dementia, results in the way care is provided and determines their quality.

The different disciplines have their own explanatory approaches, which differ but also have things in common. We carried out a conceptual analysis of the phenomenon with the question of what is meant by the phenomenon "behavioral problems". The literature search covered the years 1965 to 2012. According to stratification by years and disciplines, $10 \%$ of the articles were examined for significance for the question and finally 224 articles were analyzed and the definitions or descriptions extracted. The analysis of the texts emphasized the dominance of the medical perspective. From a medical point of view, behavioral disorders, together with deficits in cognition and effects on daily life, are an essential feature of disease definition. Also in the DSM-5 classification for neurocognitive disorders, behavioral disorders are listed as an ad- 
ditional specification feature (Maier and Barnikol 2014). From a medical perspective, behavioral problems are a symptom or side effect of dementia. Symptoms are usually treated medically in order to eliminate or at least minimize them. In the case of chronic illnesses, which include dementia, the aim of the therapy is therefore the greatest possible absence of symptoms. Applied to behavioral problems, it is therefore a matter of preventing, eliminating or at least reducing these symptoms. This understanding is the guiding principle for medical research on possible drugs against behavioral symptoms. The definition of the term neuropsychiatric symptoms and BPSD represent this medical perspective. The term "challenging behavior" is transferred from curative education to dementia care (Wüllenweber 2001). The idea behind this term is to turn away from the attribution of a behavioral problem as a sole feature of people with dementia. The "challenge" of the behavioral presentation lies in the interpersonal context. Challenging behavior is a "manifestation of distress or suffering of the person with dementia or of distress in the carer" (Bird and Moniz-Cook 2008 p. 573), and behavior that is experienced as challenging may frequently be in the eye of the beholder (Bird and Moniz-Cook 2008).

This dependency of the perspective and context is a very important feature that has influenced the understanding of the dementia related behavior and in consequence the research and discussion on this topic. In German context the term "challenging behaviors" (ger.: herausforderndes Verhalten) were introduced in Germany in 2006 with the "Rahmenempfehlungen zum Umgang mit herausforderndem Verhalten" (engl. recommendations for dealing with challenging behavior) of the Federal Ministry of Health (Bartholomeyczik et al. 2007). Since then, the term has spread to various dementia-relevant areas, not without criticism. This criticism refers to the continuing negative connotation of the term as a challenge to fight against dementia related behavior and still focusing on the behavior of people with dementia. Although the definition of the challenging behavior is not criticized, the discussion about the right name for the phenomenon is still ongoing, also internationally. Variants such as "behavior that challenges" or "challenges in behavior" are proposed as alternatives. People with dementia and their relatives prefer the terms "changed behavior(s), expressions of unmet need" or BPSD (behavioral and psychological symptoms of dementia) in a clinical context. Terms such as "behavior(s) of concern, challenging behaviors, difficult behaviors" are rejected by the people with dementia and their relatives (Alzheimer's Australia, n. d.).

The multicausality of behavioral changes is the main future of the need-driven dementia compromised model published by the research team Whall, Kolanowski and Algase in the 1990 s (Algase et al. 1996; Kolanowski 1999; Whall and Kolanowski 2004). This model represents the nursing perspective on behavioral changes and underpins the meaning of needs and the fulfillment thereof. According to the model, the need-driven dementia compromised behavior is "a most integrated and meaningful response possible, given limitations imposed by dementia, strengths preserved from the person's basic abilities and personality and environmental conditions" (Algase et 


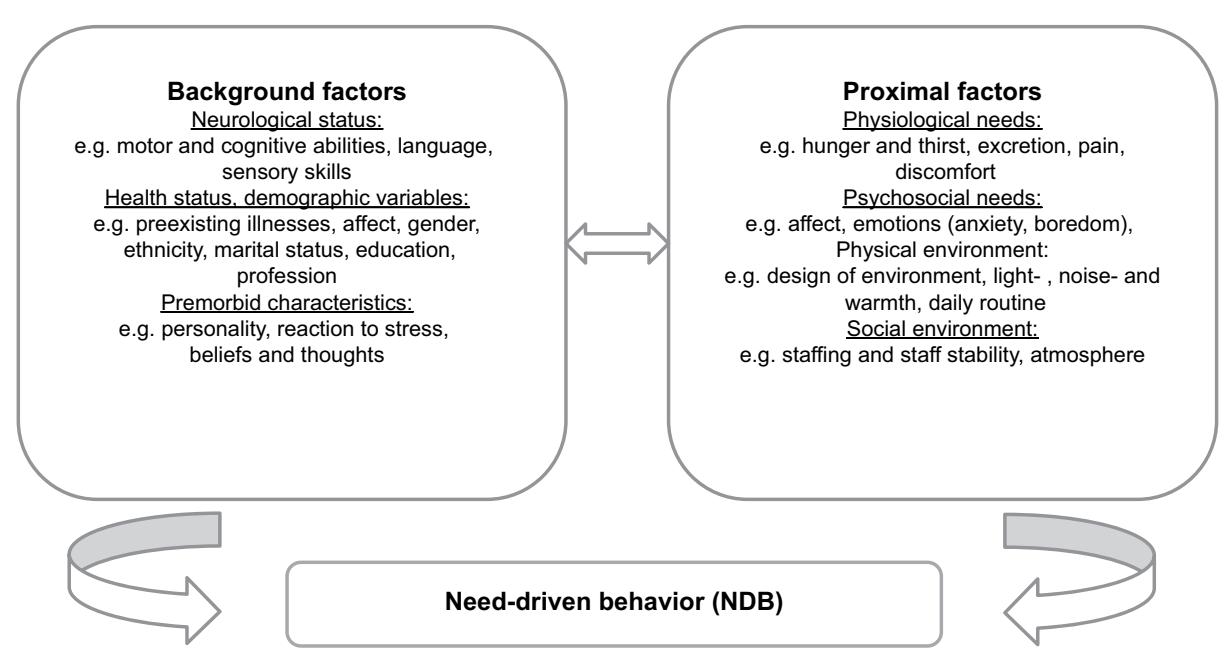

Fig. 2.1: Need-driven dementia compromised behavior model (Kolanowski 1999).

al. 1996). The key for dealing with the need-driven behavior is the recognition of the underling needs and their fulfillment. This NDB-model (fig. 2.1) introduces a positive picture of the behavior as a communication aid, as a resource or care. The challenge here is the understanding of the meaning of the behavior and to react adequately. Inadequately addressed needs cause further behavioral problems and intensify the problematic situation (Kovach et al. 2005). Similar to the NDB-model is the newest conceptional model developed by Kales and colleagues (Kales, Gitlin, and Lyketsos 2015). This model underpins the influence of dementia-related degeneration on changes in the ability of people with dementia to interact with others and the environment. The model follows two assumptions: (1) dementia can directly cause symptoms by disrupting brain circuitry involved in behavior and emotion; (2) social and physical environment can trigger behaviors independently or in interaction with the brain degeneration. The authors represent the medical perspective and use the term BPSD (Kales et al. 2015).

The distinguished psychologist Tom Kitwood represents a similar perspective with his famous work on person-centeredness by dementia (Kitwood 1997). As a result of observations in nursing homes he comes to the conclusion that behavior of people with dementia is an expression of unmeet emotional needs. He defined five psychological needs which are of a significant importance for well-being of those people: comfort, attachment, identity, inclusion and occupation. The fulfillment of these needs is the best approach in dealing with behavioral changes. Sabat and Harre understand the behavior as an attempt to re-construct the self by people with dementia. The right construction of self needs the right interpretation by others. This requires "willingness and ability of others to cooperate in the construction of a particular self" 
(Sabat and Harré 1992 p. 454). The others have to be careful listener starting from the premise that the person with dementia is trying to say something and that there is a coherent reason for the behavior in question. If the joint-construction succeeds, the person is positioned (positioning theory) correctly and the behavior is understood as manifestation of self. This is the perquisite for saving the autonomy, well-being, flourishing and dignity (Sabat and Harre 1992). From the perspective of the constructivist theory the behavior (problematic or not) is mainly a result of the social positioning and not a result of changes in the brain.

The presentation of some of the most important perspectives and definitions and a conceptual model explain the reason why there is no one universal and valid term and definition for the phenomenon "behavior by dementia". The different understandings of the phenomenon represent two different paradigms: medical and social. The differences lie in the point of the view: symptom versus the persona; in the definitory power: proxy versus self/joint; and in the goal setting: symptom reduction versus coping with the behavior. The common features are the multicausality of the behavior (pathology, state and trait of the person with dementia itself, social and physical factors) and the interaction between them.

\subsection{The nursing perspective}

The definition of the behavioral changes in dementia from the perspective of nursing science has to take into account the specific nursing focus on the caring situation. The nurses' objective is the realization the particular care task, taking into account the personal situation and needs. Success is achieved when the nursing goal (sufficient food, body care, meaningful occupation) is achieved together with the person in need of care in mutual satisfaction. Against this background, changes in behavior are understood as complex situations and the core reason for the behavioral presentation lies in the interpersonal context. The understanding of those situations requires consideration of different perspectives, in particular the perspective of those in need of care and those directly involved in the situation (professional carer or relatives). The triggers for behavioral changes can be the personal factors of the person with dementia itself (health status, personality and lifestyle) and factors from the physical and social environment. The requirement for dealing with the behavior of the person with dementia is the understanding of its function. This process of understanding of the behavior need to be systematically resulting in a common understanding of the situation, common goal setting and common handling of the situation.

The German guidelines for dealing with challenging behavior in nursing homes recommend the process of so-called "understanding diagnostic" (Bartholomeyczik 2006; Halek 2018b). The process follows the traditional nursing process: describe the behavior, analyze the triggers, decide how to act and act. The steps can be found in many other behavioral approaches (e.g. Gitlin, Kales, and Lyketsos 2012; Brechin et 
al. 2013; Jackman, Wood-Mitchell, and James 2014). The quality of the understanding process depends on the following factors: (1) taking the perspective of the person with dementia; (2) trying to understand the behavior; (3) using of a variety of behavioral explanatory aspects; (4) objectification of individual observation of behavior (creation of a common perspective on the behavior); and (5) formulation of understanding hypothesis.

Unfortunately there are few research activities that studied the perspective of the nursing and care staff on behavioral changes of people with dementia. Dupuis, Wiersma, and Loiselle (2012) interviewed 48 staff members from nursing homes about their perspective on the challenging behavior of the residents with dementia. The staff interpreted the behavior of the residents in context through a complex process. This process was dominated by a biomedical perspective. The first lens that filtered the behavior was the lens of pathology. The residents were assessed according to their illness (dementia) by every staff member subjectively. The residents with dementia were denied the sense of their behavior because "they don't know what they are doing”. In staff's eyes a cognitive impaired resident cannot be aware of right and wrong judgments. On the other hand the staff saw also behavior as a way of communication, as expression of themselves, but still in context of the disease (Dupuis et al. 2012). The advantages of this interpretation are that the staff gets an "other" understanding of the behavior; they do not take the behavior personally and have more patience, it provides another kind of interaction and it shows more compassion. The residents get a "moral status" and need a special "moral person" who is caring for them. The disadvantage of this perspective is a high risk that the behavior is interpreted as a symptom of dementia, related to brain damage and in consequence as a meaningless, aimless brain reaction. The level of challenging behavior was dependent on specific characteristics like intentionality, unpredictability and persistence, level of threatening, social appropriateness and impact on others. Again, the pathological status of the residents with dementia determined how the characteristics were assessed. All these described mean processes are individual and represent the particular perspective of the individual caregivers, resulting in different perspective on one person with dementia and a high chance of different approaches to the person. Additionally, the staff reacts usually in acute crises, which leaves any time to carefully reflect on the behavior and discuss the different variations of interpretation (Dupuis et al. 2012).

The results of this study are similar to Appelton et al. (2017) and are disappointing. Although person-centered care according to the approach described by Kitwood (1997) seems to be the gold standard for care of people with dementia, the approach described by the staff contradicts that in larger parts. The reasons can be sought in the conditions of the organization and in competences and motivation of the caregivers. The challenge of the implementation of the abstract idea of person-centeredness in the particular caring situation lies in the practical aspects, in doing. At the end, the abstract understanding of the situation has to be broken into action steps which hopefully lead to success with, for example, eating situations. 
There is scarce research that focuses on the perspective of people with dementia and their behavioral changes. This is due to the methodological and ethical challenges when examining the subjective perspective of people with dementia and their own behavior. Graneheim and colleagues (Graneheim and Jansson 2006; Graneheim, Norberg, and Jansson 2001) conducted some interviews with residents who had dementia and "disrupting behavior". The main topic of their analysis of data was "being subjected to a collapse of relations to self and others intertwined with occasional episodes of togetherness" (Graneheim and Jansson 2006 p. 1401). The people felt surrounded by disorder, trapped by restriction and set aside. Living with dementia and behavioral changes is to be excluded from meaningful relations with self and others. The others treated them as sick and restricted them. The behavior is an attempt to find freedom, to escape from unpleasant or dangerous situations. Thus, the behavior can be interpreted as a constant attempt to maintain or to rebuild one's personal self (Graneheim and Jansson 2006). The interaction with others, in particular with the care staff supports the process of personal re-construction or is disturbing and is a key element in dealing with the "disturbing" situation.

Feast and colleagues (Feast et al. 2016) worked out the perspective of family caregivers on challenging behavior of their family member with dementia in a review of qualitative and quantitative studies. According to the results the experiences of behavior as challenging by the relatives is mainly determined by communication problems. The greater the communications problems and the greater the consequences of these problems for the relatives are, the more challenging the behavior is perceived. The communication problems include the lack of interest, repetitive interaction or no meaningful discussion. These led to changes in relationships such as missed companionship and good interaction or the loss of emotional bond of love. The relatives experienced a sense of isolation and feelings of rejection and grief. In addition there exists personal expectation about the level and quality of care that the relatives should or would like to provide and that is hindered by the rejection of care. The level of frustration is also depending on the degree of tolerance and mastery or competency to respond effectively (Feast et al. 2016).

The knowledge about the three relevant perspectives underlines the significance of the view or perspective on the changes in behavior of people with dementia for understanding and dealing with the complex social situation. The attitude and interaction play a key role in this process. The view that people have on the person's challenging behavior determines the nursing care provided.

Changes in communication due to dementia are one of the main factors that explain the response of caregivers to challenging behavior. The reduction of the quality of interaction results in a decline in the relationship, particularly in families. The assumption is that successful communication and interaction can have a positive impact on experiences of challenging behavior and in consequence on development of challenging behavior. Thus the nursing work with people with dementia must be characterized by attempts to improve interaction both between nurses and persons 
with dementia as well as between family caregivers and their family members with dementia.

One step in this direction is to perceive people with dementia as interactional partners by the given change of communicative and socio-cognitive abilities according to the dimensional concept on interaction (Meyer 2014). In this theoretical work the interaction as a sociological term is extended in the four dimensions: (1) thematic continuation; (2) reference to shared knowledge; (3) formal-procedural continuation; and (4) bodily-affective responsiveness. Since the fourth dimension is becoming more and more important as dementia progresses, the work of Döttlinger (2018) is of great importance. She focused on gestural engagement of professional nurses and communication and relationship building with people with dementia. This engagement occurs "when a nursing practitioner symbolically simulates an action by means of symbolic gestures, with the aim of providing a person with advanced dementia with a reference to an action" (Döttlinger 2018). The central result is that the nurse practitioner takes the conductive and communicative responsibility for designing the interaction. Another promising approach emerged in the field of music therapy. Schumacher and colleagues (Schumacher, Calvet and Reimer 2013; Schumacher and Calvet-Kruppa 1999) worked with children with autism and developed a therapeutic instrument to assess the quality of (therapeutic) relationship (AQR) which was also used with people with dementia by Warme (2007). The aim here is to build a basis for coming in contact and develop respectively to keep self and self-efficacy as long as possible using a four-scaled instrument with six consecutive contact-modes from having no contact up to joint experience.

Concurrently a recent developed German nursing guideline for dementia (Expertenstandard) focuses on the fostering and sustaining relationship in care of people with dementia as a fundamental prerequisite for nursing activities in all care settings. The overall aim of nursing activities should be "to ensure that the person with dementia has the feeling of being heard, understood, accepted and connected with others" (Deutsches Netzwerk für Qualitätsentwicklung in der Pflege 2018).

Nevertheless, intervention addressing the caregivers' need for understanding and managing changes in communication is at an early stage of development and needs more research (Feast et al. 2016). There is no evidence on how to improve the relationship between caregivers and their relatives (Rausch, Caljouw, and van der Ploeg 2017). And there is a need to consider the specific requirements of the different forms and phases of dementia, its subtypes, and the lifespan (late/young onset).

This is the starting point for the research project AMEO-FTD ${ }^{1}$, which was conducted at the working group care interventions at the German Center of Neurodegenerative Diseases (DZNE), Witten between 2015 and 2018 (Berwig et al. 2020).

1 Application of Marte $\mathrm{Meo}^{\circledR}$-counseling with people with behavioral variant frontotemporal dementia and their primary carers (AMEO-FTD). 


\subsection{The AMEO-FTD project}

AMEO-FTD is a mixed-method feasibility study with the focus on improving the quality of dyadic relationship (one main outcome) by counselling the primary carers of people with behavioral frontotemporal dementia (bvFTD) ${ }^{2}$ in sensitive interaction using the application of video feedback according to Marte $\mathrm{Meo}^{\circledR 3}$.

In the qualitative strand of the project ${ }^{4}$ we focus amongst others on the aspect of social interaction between people with bvFTD and their primary carers in a daily life situation (having lunch). Here we wanted to know how people with bvFTD and their primary carers interact intuitively with each other, whether and how they build up a mutual relationship depending on the situation and context, and whether and how they jointly establish social order, or which means or strategies are applied.

Therefore we worked with videography based on focused ethnography (Knoblauch 2001; Knoblauch and Schnettler 2012) for data collection. Within the feasibility study mentioned above, one researcher of our research team visited five couples three times at home. After coming into contact and building trust with the participants and situation at home a video was recorded of a mealtime situation using a fixed camera. The counseling took place in a weekly rhythm over five weeks before the third visit. For the analysis of the intuitive interaction only the data of the first and second visit before the intervention period were used for interpretation. The data were analyzed by video-interaction-analysis (VIA) (Tuma, Schnettler, and Knoblauch 2013).

In the next paragraph we will present a description of a very short sequence of micro-interactions within one participating couple. We will focus on selected challenges the couple is confronted with in a daily life situation - here a mealtime situation - and discover step by step while going through the material, what is going on and how the couple adapt to these challenges or find ways to manage their daily efforts. Afterwards we will discuss the findings in light of some current theoretical considerations on interaction and dementia.

2 BvFTD is the most common subtype of young onset frontotemporal lobar degenerations (FTLD), a spectrum of neurodegenerative diseases, associated with impaired behavioral, emotional and language abilities caused by protein deposits localized in the frontal and temporal region of the brain. Clinical symptoms vary individually, but in bvFTD social cognitive abilities are primarily affected in the early stage. In this text, we are not going deep in the particularities of this special dementia subtype and we will not give recommendations on interventions. Here we focus just on a case description which serves as an example to learn about interaction.

3 Marte Meo $^{\circledast}$ (lat: “on one own’s strength”) is a video-based intervention which was initially designed for parents of children with autism to improve interactional sensitivity and create a supportive social environment for the development and maintenance of social-cognitive abilities.

4 A manuscript of complete project details and research results will be published elsewhere. 


\subsection{Case description - Mealtime at Mister and Misses B's}

\subsubsection{Background}

Mr. and Mrs. B. are approximately 60 years old and live in their own house together with two dogs in a rural area in Central Germany. They have been married for a long time and have two adult children who no longer live at home and are already independent. Mr. B. was engaged in his job working in a leading position in a nationwide company until the illness was diagnosed. Mrs. B. worked in her pedagogically oriented profession as long as possible, but after several unsuccessful attempts to allow Mr. B. to be cared for institutionally in long-term care, Mrs. B. gave up her job to devote herself entirely to care for her husband. From time to time a care assistant comes to their home when Mrs. B. can take time for errands or herself. At the time point of the video the disease was diagnosed about two and a half years ago and was already in a severe stage.

The main challenges in the common everyday life of the couple are that Mr. B. shows some degree of agitation both during the day and at night, wanders through the house and has difficulties to finish a just started action, but above all keeping the right amount of something to drink. Moreover, Mr. B. does not speak at all and does not make any other kind of verbal utterance, not even in the video recordings. Another peculiarity is that he always stands during the meal (fig. 2.2).

\subsubsection{Intro: The table is set - starting with a "still" - time code: 00:00:01}

\section{Description of room and setting}

The scene takes place in the kitchen. In the middle of the picture we see half a wooden table with a large cup with a handle and an imprint of a heart and a bone, a bowl and a spoon on the cross side and another bowl on the right side, both filled with a greenish mushy meal. A chair is placed in front of each, of which only the backrest can be seen. A fragment of a fitted kitchen made of dark brown wood can be seen on the right. On the wall hangs a small kitchen shelf of the same color with a tea towel and a potholder. Below the sideboard there is a tin can, followed by the wood-colored door frame in the middle, from where you can enter a second room, which is partly visible. The door opens inwards and connects to the wall that is on the front of the picture; further to the left is a second, but closed door that closes the picture. 


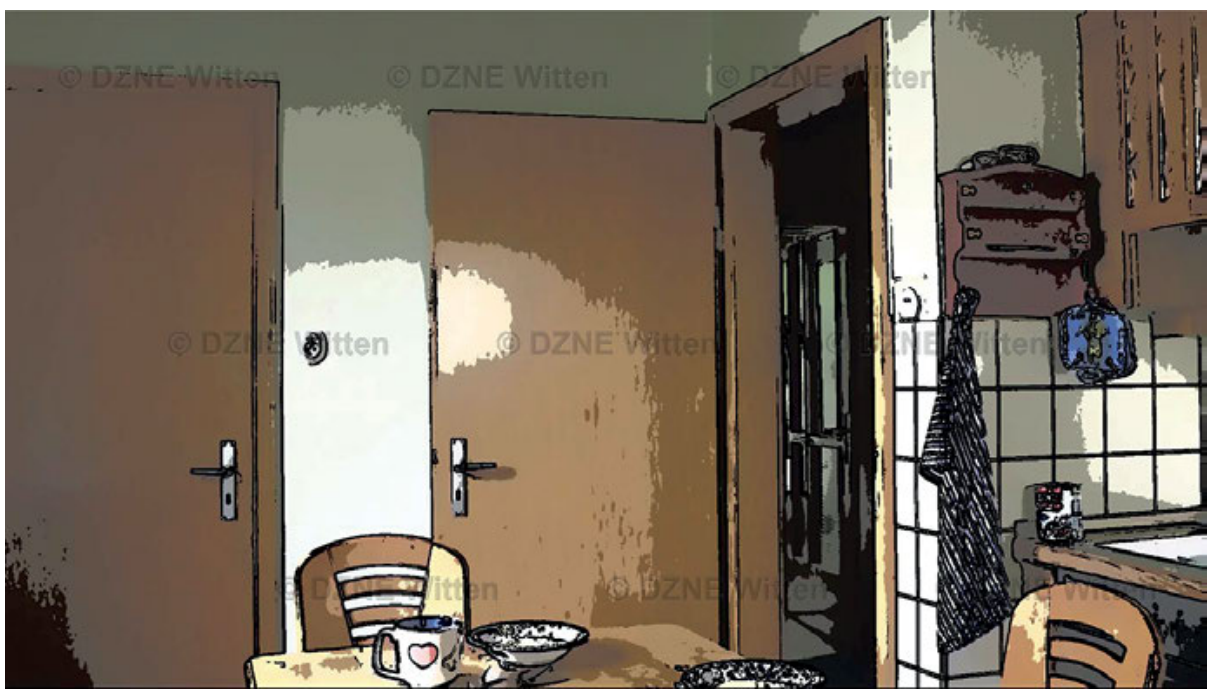

Fig. 2.2: Room and Setting.

\section{Reflections}

What do we perceive and what can we expect or anticipate?

\section{"A prepared meal, but nobody is in the room"}

The atmosphere and design of the room and its interior can be described as rather traditional and rustic and has been modern and customary about 20-30 years ago. The table is set but we don't know for sure if the meal is for breakfast, lunch or dinner; we see a cup with a heart and half of a bone on it, which can be used for coffee, tea, juice or water, but we don't see if it's filled with something. There are also two plates filled with something greenish and semifluid and there is a tin can at the sideboard.

We might associate that the heart on the cup is a symbol and stands for: "I love ..." something; the bone might be a symbol for a dog and so it might be a favorite cup for a dog enthusiast. We can also anticipate that the tin can could be filled with dog food or with soup, stew or a canned dish for the meal of two persons, because of the two plates. Even the shape of the plates might give a sign, because they are more made for eating cereals or something liquid.

But why is there nobody in the room? There might have been an interruption of the action-"having mealtime" somebody must have left the room after filling up the plates-what was the reason for leaving the room respectively and what was the reason for not coming into the room? There are several possibilities: not being hungry, just doing something more important, having a telephone call or somebody has unexpectedly knocked at the front door (post, neighbors, etc.); preparing for a meal and washing the hands; knowing that there is a camera installed and being afraid of it.

We might get some answers when starting the video. 


\subsubsection{Sequence: Coming into the room - timecode: 00:00:01-00:00:16}

\section{Description}

When starting the video sequence, there is a slight humming noise in the background-we can't see where it is coming from.

The kitchen is still empty, but we can hear somebody from outside the room, who is saying: "Come on, darling, (...) lunch".

While doing so, a woman appears in the door frame. She is dressed in a soft yellow T-shirt and blue-violet trousers, she wears glasses and her gray hair is braided into a plait that reaches down to the shoulder blades. When she comes into the room, she looks at the camera, supports herself slightly with her hand at the edge of the table and sits down on the chair to the left in the picture.

A man appears in the door frame and also comes into the kitchen. He is tall, wears a T-shirt and short sweatpants; his arms are hanging down his body, his mouth is slightly open and his eyes are directed on the bowl placed on the table.

\section{Reflections}

A noise in the kitchen might come from kitchenware; it could be a fridge, the oven, the cooker hood, the microwave, a stirrer or a special cooking pot.

The verbal expression "Come on, darling" indicates a more familiar and close relationship; “(...) lunch" is a common call to initiate the start of a mealtime, like parents do for children, when the meal is ready. Because it is the voice of a woman saying this, we can conclude that she is the one who was preparing the meal.

The first person to enter the room is the woman; she fixes the camera briefly with her eyes, but sits down without paying further attention to it, followed by the man whom she called darling before. The clothing also points to a familiar, less official situation due to sweatpants and T-shirts, which fits the situation of a kitchen as opposed to eating out in a restaurant. At this point in time, we don't know who is the one with bvFTD and who is the carer. But the fact that she is calling out and for instance his body posture (hanging arms, open mouth) may be some first hints, which we need to follow up.

In the following, we will call the man Mr. B. and the woman Mrs. B.

\subsubsection{Sequence: Starting the meal - timecode 00:00:16-00:00:40}

\section{Description}

As Mr. B. enters the room, Mrs. B. looks at his plate, takes the spoon in front of his plate, puts it in another way round and pushes his plate further to the edge of the table in his direction, looks up briefly, then to the plate and at him again (fig. 2.3). 

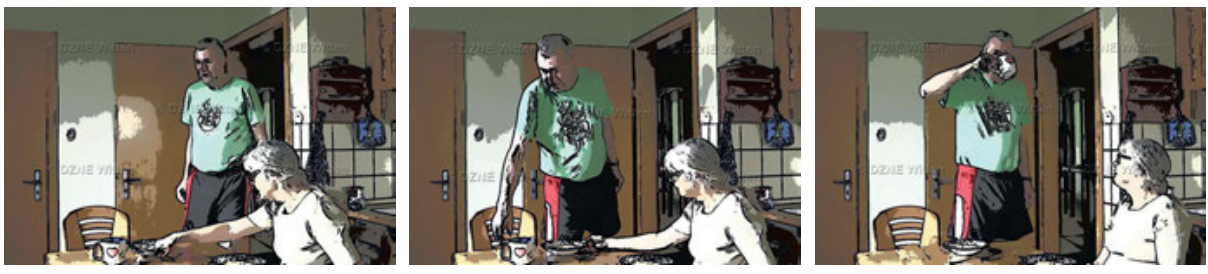

Fig. 2.3: Starting the meal.

Mr. B. walks straight towards the table, grabs the cup by the handle with his upper body slightly bent forward, leads the cup to his mouth and drinks quickly while standing, swallows, looks straight ahead over the edge of the cup, looks briefly at Mrs. B. (she nods), drinks another sip, the body swings slightly back and forth, looks directly into the camera, then back to his wife and drinks several times in a row in large swigs.

In the meantime Mrs. B. grabs her own spoon with her left hand; simultaneously she looks up at Mr. B., leans back and puts the spoon back to the left next to the plate and looks at her husband again, who is drinking, looks straight ahead, then again at Mr. B., nods to him (beeps a little) and says "Everything is ok".

\section{Reflections}

What is happening here and why are they acting in this way?

Starting a common meal: Usually one would wait until the other one sits down. If necessary one wishes good appetite and then everyone begins with the meal and eats from his own plate, with his own spoon. By turning the spoon here and pushing the plate forward, Mrs. B. leaves her territorial space and interferes with Mr. B.'s territory. Mr. B. gives no indication whether he has noticed this or whether he is comfortable with it. He goes purposefully to the table and takes the cup that - as it now becomes apparent - contains something to drink.

But if you're interpretation relies on assuming a caring act, Mrs. B. prepares here the beginning of the meal and gives Mr. B. a mark to possibly draw his attention-the act becomes a pointing gesture. It turns out bit by bit that Mrs. B. probably has the leading role.

Sitting and standing: Mr. B. himself breaks with expectations and does not sit down, even though there is a chair in front of him. Instead, he drinks quickly and in big draughts as if he is in a hurry and drinks standing up as if he wanted to leave immediately. Mrs. B., for her part, gives no indication that she thinks this situation is weird or unusual. On the contrary, she keeps eye contact and also gives a supportive and reassuring gesture of confirmation by nodding to her husband and underpins this 
with the words "Everything is ok", which is spoken here in a calming prosody. This is especially interesting, because usually the one who stands has power or dominion, which in this case is exactly the other way around, because Mrs. B. is in a spatially lower position, holds the reins and directs the situation in a gentle way.

Another question here is, what is "everything" and why does it need to be calming? Here we have some context information from the ethnographic talk before with Mrs. B., who told us, that it's unusual for Mr. B. to be eating in one turn and staying in the room for the whole dinner. Mr. B. is looking into the camera, which can be perceived as a foreign, irritating or disturbing element and could be an additional reason for the reasurrance.

Beep: There's a short beep, but permanent noise is ongoing and nobody is reacting to this.

\subsubsection{Sequence: Diverse interests - eating and keeping contact - timecode 00:00:40-00:02:10}

\section{Description}

Mr. B. drinks the cup empty and places it on the table looking at the bowl, while Mrs. B. takes his spoon, fills it with soup and puts it down on the edge so that Mr. B. can grasp it directly. When she was about to lift the filled plate, Mr. B.'s gaze wanders towards the sink and when he takes a step in that direction he is approached by Mrs. B., who puts the plate down again and softly touches the belly of Mr. B. with her flat hand, saying, "No, now here's something to eat, Harry"

Mr. B., who is about to leave, looks at her, turns right again, then to the left, coughs, seems hesitant, takes a step back and looks at the plate that Mrs. B. lifts up again. She asks him to eat again, saying, "Harry, first-take the plate in your hand, eh?"

Mr. B. takes it with both hands while Mrs. B. looks at Mr. B., waits until he takes the spoon with his right hand and begins to eat, then she turns back to her own food, eats a spoon herself, and looks up to him again, keeping eye contact as she chews, looks at Mr. B., nods to him and verbally supports the contact: "Well, it still tastes good, doesn't it?"

In the meantime Mr. B. chews, takes another spoonful, pauses, looks at Mrs. B., who also looks at him, keeps eye contact, swallows, steps from one leg to the other and then takes some soup on the spoon with the kick on his own hand several times

5 Although all participants gave written informed consent to the publication of the video data, all names are pseudonymized in this manuscript for the protection of the persons involved 

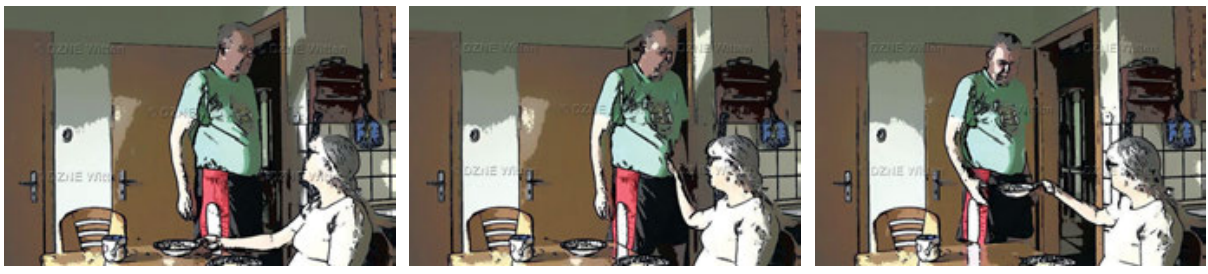

Fig. 2.4: Series of Images.

in a row, leads it to the mouth, chews 3-4 times, swallows, puts the spoon in the bowl, takes the plate in the right hand, looks up briefly and puts it back on the table.

Mrs. B. herself eats and changes her view several times and keeps looking up at Mr. B. from her plate, nods to him and finally says, "There’s plenty left" (fig. 2.4).

\section{Reflections}

Keep in touch: Before Mr. B. finishes drinking, Mrs. B. fills Mr. B.'s spoon with soup without looking at him - it seems she anticipates the next step and prepares with foresight to ensure a smooth eating process. It also seems that she suspects that Mr. B. is about to turn off the cup, so she prepares the spoon and offers him the plate so that Mr. B. can use it directly. Mr. B. has another plan, the target of which we don't know and which is somewhere out of the picture towards the sink. Mrs. B. is keeping the leading role here and prevents Mr. B. carrying out his plan and directs him by giving him a positive impulse. At the moment when she realizes that she is not being heard verbally, she acts bodily and builds up a barrier with her arm and fingers by gently touching him on his belly. In the end, Mr. B. follows her instruction hesitantly and keeps eating for about the process of eating eight spoons of soup (1.12 minutes), reaffirms himself over and over again by looking at Mrs. B., while Ms. B. keeps in constant contact by looking up again and again, keeping eye contact, nodding approvingly and encouraging him to continue eating through verbal and corporal utterances.

Add ons - the microwave and the role of the tin can: In the following scenes we will perceive that Mr. B. again tries to penetrate towards the sink and Mrs. B. again successfully prevents this request in the same way. We will also see the object of desire by seeing that Mrs. B, after Mr. B. has drunk the cup empty, pulls out a glass from behind the sink and fills it half full with mineral water several times in an elaborated and consuming process (picking it up, unscrewing it, pouring it in, screwing it down and putting it back behind the sink).

We will also learn that the sound comes from the microwave used by Mrs. B. to warm up the second portion of soup. But to prevent Mr. B. from running out of the kitchen unobserved while she has to turn her back on him, she has reserved a task for him (bringing the empty tin can into the yellow sack behind the closed door visible in the picture), which she has to assign to him and which he has to complete in this time. 
Although Mr. B. does not speak a word, he immediately understands the work order, which is verbally initiated by a pointing gesture, and acts immediately and logically. He must know where the yellow sack is and that cans belong in it. Mrs. B. pursues her concern and at the same time trusts Mr. B. to be competent in taking action.

Knowing that Mr. B. has emptied a whole case of mineral water at once in the past (context information), portioning as a restriction remains a patronizing and restrictive act, but can also be interpreted as problem solving and prevention of a major disaster. Here a dilemma situation is described in which a decision must be made between security and freedom.

\subsubsection{Concluding considerations}

Verbal communication, as described in this case, is asymmetrical and is done exclusively by Mrs. B, who says something to her husband in the context of the eating situation. Altogether Mrs. B. uses predominantly positive descriptions or prompts, like for instance: "Harry, first - take the plate in your hand, eh?" Mrs. B. has the guidance and controls the food, for example by portioning it. From time to time they have physical contact; for example, when Mrs. B. touches her husband's belly briefly and for effect, more often they have eye contact.

There are different rhythms of the eating and drinking act. It seems that Mrs. B. is in permanent attention mode and wants to prevent or counteract the interruption of the action (e. g. running out of the door). She intervenes, uses verbal descriptions and prompts him, comments on what she is doing and asks, but gets no verbal answer. Mr. B. always keeps an eye on his wife, unless he eats or looks into the camera. There are short control glances to be observed that seem insecure (standing and looking; waiting for something to drink) and a few initiated actions (move to the sink). Often Mrs. B. anticipates actions or shows that she has noticed a need of her husband and fulfils it (e. g. by pouring water), but keeping the steering position.

If we consider the present description under the slide of the dimensional concept of interaction (Meyer 2014) then we can see - focusing on Mr. B. - that we cannot find thematic continuation in this scene, because Mr. B. does not speak at all in the video recordings and does not make any other kind of verbal utterance. But what we can find is a situated and context depended understanding of shared knowledge (what to do with the empty tin can), a formal, procedural continuation in eating skills, which can be connected to rituals and a bodily-affected responsiveness, where eye focus and body turns are the main applied communicative skills.

Mrs. B. is constantly trying to keep in touch - like an invisible bond - and she uses a variety of verbal and action strategies, like a complex toolbox. This comes close to what Döttlinger (2018) called "floating attention" in her findings on interaction between people with severe dementia and specially trained nurse practitioners. This concept is characterized by an attentive visual observation of the communication 
partner - the professional nurse keeps the contact and remains continuously "in suspension" and keeps contact. At the same time, the nurse remains in "responsiveness with expectation", which means that a reaction to an "utterance of the person with dementia" can take place immediately when a necessity is recognized from the floating attentive posture. Which reaction is chosen depends on the situation. In our case Mrs. B. is taking this responsibility for the interaction as well, even if there is no specialized training program before. In our video sequence we reconstructed step by step that she is taking the lead to "hold on doing the common meal", which can be allocated in the broadest sense as what we described in this manuscript as the "nursing perspective". Before building this kind of skill in a daily care situation, she has to accept that she is "living with a partner who has dementia" and actively take the carer role. The latter is a main result of the AMEO-FTD Study (Berwig et al. 2020, accepted) and one key element in the stability of care arrangements in home care settings (Köhler et al. 2018). That she is doing it in this sequence in a protective but gentle way might depend on some "intuitive caring skills" and her pedagogic background (contextual information). It can also be described as a person-centered approach, oriented on an underlying frame to as much as possible build a symmetric connection in an asymmetric relationship. In ethnomethodological terms, she is repairing the given crisis in a continuous and situational mutual interactive negotiation and so, both $\mathrm{Mr}$. and Mrs. B. create together their own common order.

\subsection{Conclusion}

Finally, we can summarize that the dyadic interaction we perceived in this short video sequence of one person with dementia and his caring wife served as an example of remaining individual and is generated situationally and at a micro level. Yet this confirms once again that an understanding approach to behavioral challenges of people with dementia is a prerequisite for successful interaction, based on a relational and continuous basis, even if reciprocity cannot be assumed or established in all moments. "Making and keeping contact" is a key factor and is established in ultrashort moments and at different levels and modes. If behavior is understood to be meaningful, then the challenge may no longer be experienced in a stressful way. Video feedback is a method of visualizing the microstructure of interaction and has potential to train people with dementia and their carers and might help to stabilize the relationship. 


\section{References}

Algase, Donna L., Cormelia Beck, Ann Kolanowski, Ann Whall, Stanley Berent, Kathy Richards, and Elizabeth Beattie. 1996. Need-driven dementia-compromised behavior: An alternative view of disruptive behavior. American Journal of Alzheimer's Disease 11 (6): 10-19. doi: $10.1177 / 153331759601100603$.

Alzheimer's Australia. n. d. Dementia Language Guidelines. https://www.dementia.org.au/resources/dementia-language-guidelines. Accessed 26 June 2019.

Appleton, Katie, and Antonina Pereira. 2019. Behavioural Changes in Dementia and their Impact on Professional Caregivers: A Grounded Theory Approach. Dementia 18 (4): 1479-1491. doi: $10.1177 / 1471301217714654$.

Bartholomeyczik, Sabine. 2006. Rahmenempfehlungen zum Umgang mit herausforderndem Verhalten bei Menschen mit Demenz. Pflegen: Demenz 1: 1-4.

Bartholomeyczik, Sabine, Margareta Halek, Christine Sowinski, Klaus Besselmann, Peter Dürrmann, Martin Haupt, Christina Kuhn, Christian Müller-Hergl, Klaus Maria Perrar, Christine Riesner, Detlef Rüsing, Ruth Schwerdt, Cora van der Kooij, and Angelika Zegelin. 2007. Rahmenempfehlungen zum Umgang mit herausforderndem Verhalten bei Menschen mit Demenz in der stationären Altenhilfe. Berlin: Bundesministerium für Gesundheit.

Berwig, M., Dinand, C., Becker, U., Halek, M. 2020. Application of MarteMeo ${ }^{\circledR}$ counselling with people with behavioural variant frontotemporal dementia and their primary carers (AMEO-FTD) a non-randomized mixed method feasibility study. Pilot and Feasibility Studies, https://doi. org/10.1186/s40814-020-0551-1.

Bird, Mike, and Esme Moniz-Cook. 2008. Challenging Behaviour in Dementia: A Psychosocial Approach to Intervention. In Handbook of the Clinical Psychology of Ageing, ed. Bob Woods and Linda Clare, 571-594. Chichester, UK: John Wiley \& Sons, Ltd.

Borsje, Petra, Roland B. Wetzels, Peter L. Lucassen, Anne Margriet Pot, and Raymond T. Koopmans. 2015. The course of neuropsychiatric symptoms in community-dwelling patients with dementia: a systematic review. International Psychogeriatrics 27 (3): 385-405. doi: 10.1017/ S1041610214002282.

Brechin, Donald, Gemma Murphy, Andrew James, and Jason Codner. 2013. Alternatives to antipsychotic medication. Psychological approaches in managing psychological and behavioural distress in people with dementia. Leicester: British Psychological Society.

Cohen-Mansfield, J., M. S. Marx, and A. S. Rosenthal. 1989. A description of agitation in a nursing home. Journal of Gerontology 44 (3): M77-84. doi: 10.1093/geronj/44.3.m77.

Cummings, J. L. 1997. The Neuropsychiatric Inventory: assessing psychopathology in dementia patients. Neurology 48 (5 Suppl 6): S10-6. doi: 10.1212/wnl.48.5_suppl_6.10 s.L42:URLEND

Deutsches Netzwerk für Qualitätsentwicklung in der Pflege. 2018. Expertenstandard „Beziehungsgestaltung in der Pflege von Menschen mit Demenz. Osnabrück: DQNP.

Döttlinger, Beatrix. 2018. Gestisch-kommunikatives Handeln als Bindeglied zwischen Sprache und Handeln bei Menschen mit Demenz. Beziehungs- und Interaktionsgestaltung. Weinheim, Basel: Beltz.

Dupuis, Sherry L., Elaine Wiersma, and Lisa Loiselle. 2012. Pathologizing behavior: Meanings of behaviors in dementia care. Journal of Aging Studies 26 (2): 162-173. doi: 10.1016/j. jaging.2011.12.001.

Feast, Alexandra, Esme Moniz-Cook, Charlotte Stoner, Georgina Charlesworth, and Martin Orrell. 2016. A systematic review of the relationship between behavioral and psychological symptoms (BPSD) and caregiver well-being. International psychogeriatrics 28 (11): 1761-1774. doi: 10.1017/ S1041610216000922.

Feast, Alexandra, Martin Orrell, Georgina Charlesworth, Nina Melunsky, Fiona Poland, and Esme Moniz-Cook. 2016. Behavioural and psychological symptoms in dementia and the challenges 
for family carers: systematic review. The British journal of psychiatry 208 (5): 429-434. doi: 10.1192/bjp.bp.114.153684.

Gitlin, Laura N., Helen C. Kales, and Constantine G. Lyketsos. 2012. Managing Behavioral Symptoms in Dementia Using Nonpharmacologic Approaches: An Overview. JAMA 308 (19): 2020-2029. doi: 10.1001/jama.2012.36918.

Graneheim, Ulla H., and Lilian Jansson. 2006. The meaning of living with dementia and disturbing behaviour as narrated by three persons admitted to a residential home. Journal of Clinical Nursing 15 (11): 1397-1403. doi: 10.1111/j.1365-2702.2006.01476.x.

Graneheim, Ulla H., A. Norberg, and L. Jansson. 2001. Interaction relating to privacy, identity, autonomy and security. An observational study focusing on a woman with dementia and „behavioural disturbances “, and on her care providers. Journal of advanced nursing 36 (2): 256-265. doi: 10.1046/j.1365-2648.2001.01966.x.

Halek, Margareta. 2018. Wann ist Verhalten herausfordernd?: Die Antwort ist eine Frage der Perspektive. Pflegen: Demenz 56: 44-48.

Halek, Margareta. 2019. Das Verhalten von Mensche mit Demenz verstehen - Ansätze für Interventionen. In Demenz - Prävention und Therapie: Ein Handbuch der komplementärmedizinischen und nichtmedikamentösen Verfahren, ed. Harald Walach and Martin Loef, 417-438. Essen: KVC Verlag.

Halek, Margareta. 2019. Verstehende Diagnostik als Hilfe im Umgang mit Verhaltensveränderungen von Menschen mit Demenz. Blätter der Wohlfahrtspflege 2 (166): 61-65.

International Psychogeriatric Association (IPA). 2012. Behavioral and Psychological Symptoms of Dementia (BPSD). http://www.bsa.ualberta.ca/sites/default/files/ IPA_BPSD_Specialists_ Guide_Online.pdf. Accessed 9 September 2019.

Jackman, Louisa J., Amy Wood-Mitchell, and Ian A. James. 2014. Micro-skills of group formulations in care settings. Dementia 13 (1): 23-32. doi: 10.1177/1471301212442463.

Kales, H. C., L. N. Gitlin, and C. G. Lyketsos. 2015. Assessment and management of behavioral and psychological symptoms of dementia. BMJ 350 (7): h369-h369. doi: 10.1136/bmj.h369.

Kitwood, T. M. 1997. Dementia reconsidered. The person comes first. Buckingham: Open University Press.

Knoblauch, Hubert. 2001. Fokussierte Ethnographie. Sozialer Sinn 2 (1). doi: 10.1515/ sosi-2001-0105.

Knoblauch, Hubert, and Bernt Schnettler. 2012. Videography: analysing video data as a 'focused' ethnographic and hermeneutical exercise. Qualitative Research 12 (3): 334-356. doi: $10.1177 / 1468794111436147$.

Köhler, K., J. Dreyer, I. Hochgraeber, and B. Holle. 2019. Stability of home-based care arrangements for people living with dementia: A midrange theory developed from a meta-study on mixed research. Paper presented at the International Association of Gerontology and Geriatrics European Region Congress 2019 (IAGG-ER 2019)23.05.2019-25.05.2019. Gothenburg.

Kolanowski, A. M. 1999. An overview of the need-driven dementia-compromised behavior model. Journal of Gerontological Nursing 25 (9): 7-9.

Kovach, Christine R., Patricia E. Noonan, Andrea Matovina Schlidt, and Thelma Wells. 2005. A Model of Consequences of Need-Driven, Dementia-Compromised Behavior. Journal of Nursing Scholarship 37 (2): 134-140. doi: 10.1111/j.1547-5069.2005.00025_1.x.

Kunik, M. E., A. L. Snow, J. A. Davila, T. McNeese, A. B. Steele, V. Balasubramanyam, R. Doody, P. E. Schulz, J. S. Kalavar, A. Walder, and R. O. Morgan. 2010. Consequences of Aggressive Behavior in Patients With Dementia. Journal of Neuropsychiatry 22 (1): 40-47. doi: 10.1176/appi. neuropsych.22.1.40. 
Maier, W., and U. B. Barnikol. 2014. Neurokognitive Störungen im DSM-5 : Durchgreifende Anderungen in der Demenzdiagnostik. Der Nervenarzt 85 (5): 564-570. doi: 10.1007/ s00115-013-3984-4.

Meyer, Christian. 2014. Menschen mit Demenz als Interaktionspartner. Eine Auswertung empirischer Studien vor dem Hintergrund eines dimensionalisierten Interaktionsbegriffs / People with Dementia as Interactional Partners: An Analysis of Empirical Studies Based on a Dimensional Concept of Interaction. Zeitschrift für Soziologie 43 (2): 531. doi: 10.1515/zfsoz-2014-0203.

Möller, H.-J., and M. B. Graeber. 1998. The case described by Alois Alzheimer in 1911. European Archives of Psychiatry and Clinical Neuroscience 248 (3): 111-122. doi: 10.1007/s004060050027.

Moniz-Cook, Esme, Myrra Vernooij-Dassen, Bob Woods, Martin Orrell, and Interdem Network. 2011. Psychosocial interventions in dementia care research: The INTERDEM manifesto. Aging \& Mental Health 15 (3): 283-290. doi: 10.1080/13607863.2010.543665.

Rausch, Annemarie, Monique A. A. Caljouw, and Eva S. van der Ploeg. 2017. Keeping the person with dementia and the informal caregiver together: a systematic review of psychosocial interventions. International Psychogeriatrics 29 (4): 583-593. doi: 10.1017/S1041610216002106.

Reisberg, Barry, Stefanie R. Auer, and Isabel M. Monteiro. 1997. Behavioral Pathology in Alzheimer's Disease (BEHAVE-AD) Rating Scale. International Psychogeriatrics 8 (S3): 301-308. doi: 10.1017/ S1041610297003529.

Sabat, Steve R., and Rom Harré. 1992. The Construction and Deconstruction of Self in Alzheimer's Disease. Ageing and Society 12 (4): 443-461. doi: 10.1017/S0144686X00005262.

Schumacher, Karin, Claudine Calvet, and Silke Reimer. 2013. Das EBQ-Instrument und seine entwicklungspsychologischen Grundlagen. Göttingen: Vandenhoek \& Ruprecht.

Schumacher, Karin, and Claudine Calvet-Kruppa. 1999. The "AQR" - an Analysis System to Evaluate the Quality of Relationship during Music Therapy. Nordic Journal of Music Therapy 8 (2): 188-191. doi: 10.1080/08098139909477974.

Synder, L. H., P. Rupprecht, J. Pyrek, S. Brekhus, and T. Moss. 1978. Wandering. The Gerontologist 18 (3): 272-280. doi: 10.1093/geront/18.3.272.

Teipel, Stefan J., Jochen René Thyrian, Johannes Hertel, Tilly Eichler, Diana Wucherer, Bernhard Michalowsky, Ingo Kilimann, and Wolfgang Hoffmann. 2015. Neuropsychiatric symptoms in people screened positive for dementia in primary care. International Psychogeriatrics 27 (1): 39-48. doi: 10.1017/S1041610214001987.

Thyrian, J. R., Eichler T, Hertel J, Wucherer D, Dreier A, Michalowsky B, Killimann I, Teipel S, and Hoffmann W. 2015. Burden of Behavioral and Psychiatric Symptoms in People Screened Positive for Dementia in Primary Care: Results of the DelpHi-Study. Journal of Alzheimer's Disease 46 (2): 451-459.

Toot, Sandeep, Mike Devine, Ajiri Akporobaro, and Martin Orrell. 2013. Causes of Hospital Admission for People With Dementia: A Systematic Review and Meta-Analysis. Journal of the American Medical Directors Association 14 (7): 463-470. doi: 10.1016/j.jamda.2013.01.011.

Toot, Sandeep, Tom Swinson, Mike Devine, David Challis, and Martin Orrell. 2017. Causes of nursing home placement for older people with dementia: a systematic review and meta-analysis. International Psychogeriatrics 29 (2): 195-208. doi: 10.1017/S1041610216001654.

Tuma, René, Hubert Knoblauch, and Bernt Schnettler. 2013. Videographie. Einführung in die interpretative Videoanalyse sozialer Situationen. Wiesbaden: Springer VS.

Warme, Britta. 2007. Musiktherapie als Gruppenpsychotherapie mit an Demenz erkrankten Menschen. Musiktherapeutische Umschau 28 (4): 329-339. doi: 10.13109/muum.2007.28.4.329.

Whall, A. L., and A. M. Kolanowski. 2004. The need-driven dementia-compromised behavior model-a framework for understanding the behavioral symptoms of dementia. Aging \& Mental Health 8 (2): 106-108. 
Wüllenweber, E. 2001. Verhaltensprobleme als Bewältigungsstrategie. In Verhaltensauffälligkeiten - Ausdruck von Selbstbestimmung?: [Wegweisende Impulse für heilpädagogische, therapeutische und alltägliche Arbeit mit geistig behinderten Menschen], vol. 2, ed. Georg Theunissen, 89-103, 2nd edn. Bad Heilbrunn: Klinkhardt 